\title{
A diversidade cultural como potência pedagógica: do encontro à educação intercultural
}

\author{
The cultural diversity as pedagogical power: from the meeting to the \\ intercultural education
}

\section{La diversidad cultural como potencia pedagógica: del encuentro a la educación intercultural}

\author{
Ana Tereza Reis da Silua' \\ Universidade de Brasília, Faculdade de Educação, Professora. \\ http://orcid.org/0000-0001-8204-0732 \\ lassana Rodrigues Soares ${ }^{2}$ \\ Secretaria de Estado de Educação do Distrito Federal, Professora. \\ https://orcid.org/0000-0001-5088-4535
}

Resumo: Neste artigo, analisamos a diversidade cultural e os encontros interculturais que tomam lugar na Escola Classe Sítio das Araucárias, situada na Rota do Cavalo, Sobradinho-DF. A pesquisa empírica que informa o artigo foi realizada ao longo do ano de 2019 por meio de entrevistas e rodas de conversa junto à equipe docente da Escola e de observação participante junto às famílias que habitam na região, em seus espaços coletivos e territórios de vivências. A partir desses dois procedimentos metodológicos, analisamos a feição da diversidade cultural que constitui a Rota do Cavalo e as formas pelas quais ela têm sido, ao mesmo tempo, afirmada, negada, marcada e comungada no contexto escolar. Com base nisso, analisamos os desafios pedagógicos que brotam do convívio com a diferença, bem como indicamos algumas potencialidades que o encontro intercultural aponta com vistas à construção de uma educação intercultural criticamente orientanda.

Palavras-chave: Diversidade Cultural. Diálogo Intercultural; Educação Intercultural Crítica.

Abstract: In this article, we analyze the cultural diversity and intercultural encounters that take place at the school Escola Classe Sitio das Araucárias, located in Rota do Cavalo, Sobradinho-DF. The empirical research that informs the article was carried out throughout 2019 by means of interviews and rounds of conversation with the School's teaching staff and by means of participant observation with families

Doutora em Desenvolvimento e Meio Ambiente pela Universidade Federal do Paraná (UFPR); Líder do Grupo de Pesquisa Educação, Saberes e Decolonialidades (Gpdes/CNPq).

2 Mestre em Educação pela Universidade de Brasília; Pesquisadora do Grupo de Pesquisa Educação Saberes e Decolonialidades (Gpdes/CNPq). 
living in the region, in their collective spaces and territories of experiences. Based on these two methodological procedures, we analyze the cultural diversity that constitutes the Horse Route and the ways in which it has been, at the same time, affirmed, denied, marked and shared in the school context. Based on this, we analyze the pedagogical challenges that arise from living with difference, as well as indicate some potentials that the intercultural encounter points out with a view to building a critically oriented intercultural education.

Keywords: Cultural Diversity. Intercultural Dialogue. Critical Intercultural Education.

Resumen: En este artículo analizamos la diversidad cultural y los encuentros interculturales que tienen lugar en la escuela Escola Classe Sitio das Araucárias, ubicada en Rota do Cavalo, Sobradinho-DF. La investigación empírica que informa el artículo se realizó a lo largo de 2019 a través de entrevistas y rondas de conversación con el profesorado de la Escuela y a través de observación participativa con las familias residentes en la región, en sus espacios colectivos y territorios de vivencias. A partir de estos dos procedimientos metodológicos, analizamos la diversidad cultural que constituye la Ruta del Caballo y las formas en que ha sido, al mismo tiempo, afirmada, negada, marcada y compartida en el contexto escolar. En base a esto, analizamos los desafios pedagógicos que surgen de vivir con la diferencia, así como señalamos algunas potencialidades que apunta el encuentro intercultural con miras a construir una educación intercultural de orientación crítica.

Palabras clave: Diversidad cultural. Diálogo intercultural; Educación crítica intercultural.

Recebido em 15 de julho de 2020 Aceito em 28 de fevereiro de 2021

\section{INTRODUÇÃO}

A Escola Classe Sitio das Araucárias, contexto desta pesquisa, acolhe uma expressiva diversidade cultural, social, religiosa e étnica. A escola está situada em uma área rural da região administrativa ${ }^{3}$ de Sobradinho-DF, denominada "Rota do Cavalo", onde vivem famílias e grupos sociais e étnicos que, majoritariamente, dedicam-se à lida com a terra, turismo rural e criação. A Escola faz parte do quadro de Instituições Públicas da Secretaria do Estado de Educação do Distrito Federal, no âmbito do qual é classificada como "Escola do Campo".

Nesse contexto, nosso olhar se volta para a diversidade da Rota do Cavalo, que chega à Escola Classe Sítio das Araucárias pela presença das(os) estudantes, onde

3 Diferentemente dos estados brasileiros que são formados por municípios, o Distrito Federal (DF) é constituído por Regiões Administrativas (RAs). Cada Região possui um órgão administrativo próprio vinculado à administração distrital. 
é atravessada pelos encontros interculturais (inerentes à convivência) e consequentes processos de afirmação, negação, marcação e comunhão das diferenças.

A pesquisa empírica que informa o artigo foi realizada ao longo do ano de 2019 por meio de rodas de conversa junto à equipe docente da Escola e de observação participante junto aos grupos sociais e famílias que habitam na região, em seus espaços coletivos que constituem os territórios de vivência das(os) estudantes: quintais, eventos, festejos, plantios, colheitas, reuniões. A partir desses dois procedimentos metodológicos, analisamos a feição da diversidade que constitui a Rota do Cavalo e os atravessamentos que ela experimenta no contexto escolar.

No diálogo com a equipe docente, buscamos compreender se a diversidade cultural influencia no trabalho pedagógico, isto é, como é reconhecida e incorporada em suas práticas pedagógicas. Com base nos relatos orais coletados nas rodas de conversas e nas entrevistas, empreendemos duas análises articuladas: 1) que os atravessamentos da diversidade no contexto escolar envolvem processos de afirmação, negação, marcação e comunhão da diferença; 2) que o encontro intercultural é um campo aberto a ser explorado pedagogicamente para favorecer o diálogo e, consequentemente, a educação intercultural.

0 texto está organizado em quatro seções, além desta introdução e as considerações finais. Na primeira seção, narramos o percurso metodológico, detalhando os procedimentos, indicando os lugares nos quais estivemos e as pessoas que foram nossas interlocutoras. Na segunda seção, com base na observação participante, apresentamos a diversidade cultural que compõe a rota do cavalo e que chega à escola pela presença das(os) estudantes. Na terceira seção, a partir das narrativas das docentes coletadas nas rodas de conversas, analisamos os desafios pedagógicos que brotam do convívio com a diferença e que emergem como barreiras e/ou potencialidades para a construção de uma prática educativa sensivel ao colhimento da diversidade. Na quarta seção, indicamos algumas potencialidades que o encontro intercultural aponta com vistas à construção de uma educação intercultural criticamente orientanda.

\section{O PERCURSO METODOLÓGIICO}

0 percurso metodológico se deu no cotidiano da Escola Classe Sítio das Araucárias e nos territórios de vivência das(os) estudantes. A temática da diversidade cultural que atravessa a Escola foi mapeada e analisada tendo como base as rodas de conversas realizadas com a equipe docente da Escola (professoras, coordenadora pedagógica, gestora e equipe de apoio), no período de junho a dezembro de 2019, bem como por meio de observação 
participante em reuniões plantios, colheitas e festejos junto aos acampamentos Renascer Palmares, Marias da Terra, Margarida Alves e Cigano, Rancho São Jorge, chácaras Flor do Cerrado e Boa Esperança e Fazenda Sálvia.

Nas etapas um e dois, mapeamos o conhecimento da equipe sobre a diversidade cultural e os saberes que atravessam o cotidiano escolar. Na etapa três, buscamos identificar de que forma a diversidade cultural está presente nas reflexões das(os) professoras, e em que medida influencia suas práticas pedagógicas.

$\mathrm{Na}$ etapa quatro, aprofundamos as questões discutidas nas etapas anteriores acerca dos processos de negação, afirmação e comunhão da diversidade. Na etapa cinco, realizamos entrevista semiestruturada com duas professoras que ocupam funções de gestão, visando compreender a construção de ações e estratégias (Planejamento, Projetos, Organização Administrativa, etc.) voltadas ao acolhimento da diversidade cultural.

Durante a observação participante interagimos com diferentes famílias e grupos sociais e étnicos. No Acampamento Renascer Palmares, acompanhamos a rotina da liderança Rita de Cássia e seus familiares na colheita do milho, na preparação da Festa da Pamonha e na roda de conversa com a moradora Fátima Alves sobre os fundadores do acampamento e as memórias afetivas do lugar. No acampamento Marias da Terra, participamos de reuniões em que a comunidade discutiu a necessidade de implantação de uma escola tenda. No acampamento Cigano, vivenciamos os festejos em comemoração aos cincos anos da chegada do grupo no território, a inauguração de uma escola tenda e o lançamento do livro de Lenilda Perpétuo, intitulado Ciganidade e educação escolar: saber tradicional e conflito étnico, fruto de sua dissertação de mestrado (2017). Também acompanhamos a rotina de famílias agricultoras e pecuaristas e participamos de duas atividades extraclasse da escola no Rancho São Jorge e na chácara Flor do Cerrado, em comemoração à Semana da Criança.

Os diálogos e relatos orais coletados nas interações com as famílias e espaços coletivos da comunidade foram filmados, gravados e anotadas em diário de campo. A partir daí, identificamos os grupos sociais e étnicos que compõem a Rota do Cavalo. Nas duas primeiras rodas de conversa com as(os) docentes, também realizamos um levantamento sobre as origens e os pertencimentos identitários das(os) estudantes, bem como sobre seus principais territórios de vivência.

A partir desse mapeamento da diversidade cultural, via comunidade e via escola, construímos um quadro e um gráfico, apresentados a seguir, que auxiliaram nos debates das rodas de conversa, assim como orientaram nosso olhar durante as atividades de observação participante. 
Quadro 1 - Atividades econômicas e respectivos espaços onde são desenvolvidas

\begin{tabular}{|c|c|}
\hline Atividades econômicas & Espaços onde são desenvolvidas \\
\hline $\begin{array}{l}\text { Atividades ligadas ao turismo rural, criação de ani- } \\
\text { mais de pequeno poder, cavalos e empreendimentos } \\
\text { de lazer. }\end{array}$ & $\begin{array}{l}\text { Haras, ranchos, hotel fazenda, hípica, casa de chá } \\
\text { colonial; }\end{array}$ \\
\hline $\begin{array}{l}\text { Atividades diversas ligadas à produção e manejo da } \\
\text { terra: meeiros, produtores, agricultores, criadores. }\end{array}$ & $\begin{array}{l}\text { Chácaras, sítios, fazendas e Acampamento Renascer } \\
\text { Palmares; }\end{array}$ \\
\hline $\begin{array}{l}\text { Atividades agrícolas ligadas à luta pela terra: Movi- } \\
\text { mentos de Apoio aos Trabalhadores Rurais (MATR), } \\
\text { Movimento dos Trabalhadores Rurais Sem Terra (MST), } \\
\text { do Movimento de Luta pela Terra (MLT), o Movimento } \\
\text { de Trabalhadores Sem Teto (MTST), Frente Nacional de } \\
\text { Luta (FNL) e os Ciganos da etnia Calon. }\end{array}$ & $\begin{array}{l}\text { Acampamento Canaã, } \\
\text { Acampamento Dorothy Stang, } \\
\text { Acampamento Margarida Alves, Acampamento Marias } \\
\text { da Terra, Acampamento Nelson Mandela, } \\
\text { Acampamento Pôr do Sol, } \\
\text { Acampamento Primavera, } \\
\text { Acampamento Renascer Palmares; }\end{array}$ \\
\hline $\begin{array}{l}\text { Abrigo e acolhimento de crianças em situação de } \\
\text { vulnerabilidade familiar e social. }\end{array}$ & Lar Jesus Menino; \\
\hline $\begin{array}{l}\text { Moradias derivadas de recentes processos de } \\
\text { urbanização e ordenamento territorial: condomínios } \\
\text { verticais. }\end{array}$ & $\begin{array}{l}\text { Condomínio Serra Verde, Condomínio e Setor Habita- } \\
\text { cional Nova Colina, e outras áreas. }\end{array}$ \\
\hline
\end{tabular}

Fonte: os autores.

Gráfico 1 - Diversidade cultural na escola expressa em matrículas

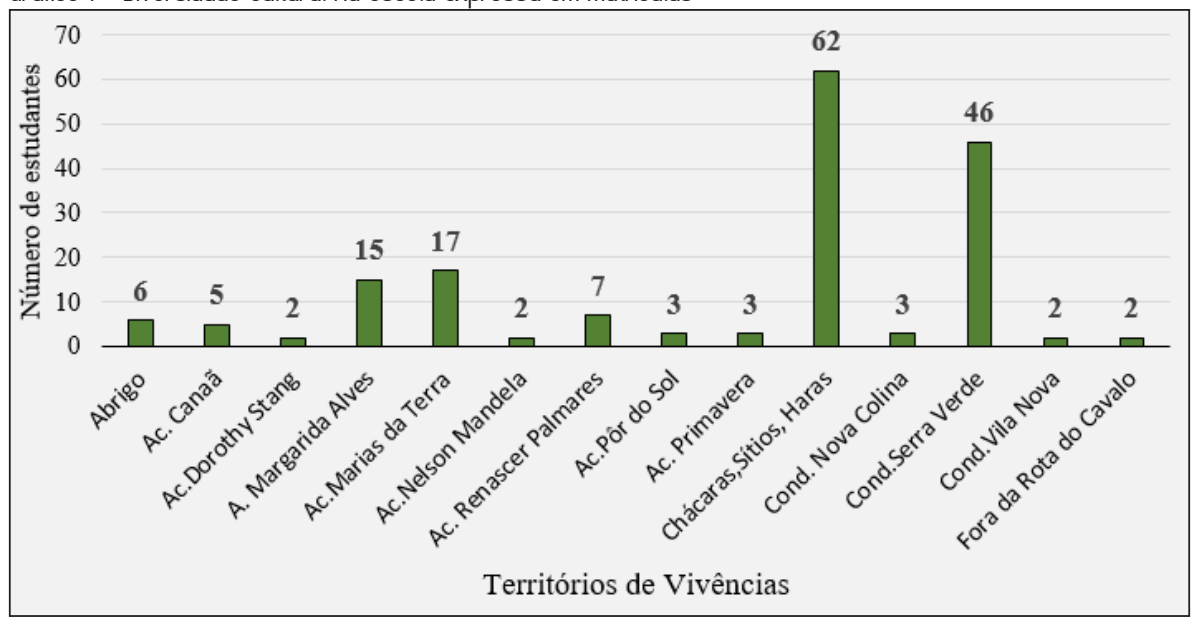

Fonte: os autores.

0 Quadro 1 exibe as atividades econômicas predominantes e os grupos sociais que a elas se dedicam, bem como os espaços (territórios vivenciais) onde essas atividades são desenvolvidas. A população da região expressa, como se pode constatar, trajetórias 
históricas e sociais diversas que convergiram para a Rota do Cavalo: ciganos, famílias ligadas à luta pela terra, pequenos agricultores e empreendedores de turismo e outros negócios rurais, moradores de condomínios residenciais, crianças de abrigo. Como se pode ver no Gráfico 1, essa diversidade chega à Escola, predominantemente, pela presença de crianças provenientes dos sítios, fazendas e chácaras mais antigas, dos condomínios residenciais, das famílias de acampados, assentados e do povo cigano da etnia Calon.

Neste artigo, não trataremos dos processos históricos que levaram esses grupos à Rota do Cavalo, nem dos conflitos sociais e disputas territoriais que certamente emergem aí. Nosso foco será a diversidade que chega à Escola, que produz o inescapável encontro intercultural, que gera tensionamentos e atravessamentos, assim como impõe à equipe docente desafios e oportunidades para explorar a potência pedagógica da diversidade cultural, visando a construção de práticas acolhedoras da diferença e promovedoras do diálogo e de uma educação intercultural.

\section{A DIUERSIDADE CULTURAL NA ROTA DO CAUALO}

Há registros de que a região, hoje conhecida como Rota do Cavalo, zona rural de Sobradinho-DF, é ocupada há mais de um século, antes mesmo do surgimento do Distrito Federal (DF), quando a região ainda pertencia ao estado de Goiás. As ocupações mais antigas são fazendas e chácaras de pequenos proprietários de terra, dedicadas principalmente à agricultura, criação de animais de pequeno porte e cavalos.

Embora a ocupação da região seja antiga, o nome Rota do Cavalo e as feições atuais da ocupação territorial e da diversidade cultural são relativamente recentes. Um informativo publicado pela Secretaria de Turismo do Distrito Federal (SETUR-DF) indica que o nome "Rota do Cavalo" foi definido em reunião realizada em 1997, da qual participaram os proprietários de terra residentes na região e servidores da SETUR-DF. A ideia do nome veio, segundo consta do referido informativo, da necessidade de destacar e explorar o potencial turístico do principal aspecto econômico da região - haras e empreendimentos relacionados ao mercado equestre que havia experimentado um significativo aumento nas últimas três décadas.

Em 2007, a SETUR-DF, em parceria com a Administração Regional de Sobradinho e órgãos do Governo do Distrito Federal (GDF), iniciou a implementação de um programa de mesmo nome (Rota do Cavalo) com o objetivo de fortalecer o turismo associado às manifestações culturais que acontecem na região (vaquejadas, leilões, exposições agropecuárias, rodeios, atividades equestres). Desde então, a Rota do Cavalo tem sido promovida e divulgada como 
uma região predominantemente dedicada a essas atividades econômicas (GOVERNO DO DISTRITO FEDERAL, 2018).

Esse processo, liderado principalmente pelo poder público em parceria com os proprietários de grandes áreas, não leva em conta as atividades voltadas para a produção da existência e luta pela terra; e, portanto, não inclui as famílias e grupos que as desenvolvem. Dentre esses grupos, que têm se instalado na região nos últimos 20 anos, estão assentados da Reforma Agrária, acampadas do Movimento de Apoio aos Trabalhadores Rurais (MATR) e do Movimento Sem Terra (MST), famílias do Movimento de Luta pela Terra (MLT), do Movimento de Trabalhadores Sem Teto (MTST), da Frente Nacional de Luta (FNL) e Ciganos da Etnia Calon.

A Escola Classe Sítio das Araucárias foi fundada em 1985 para atender as crianças das famílias e proprietários de terra que residiam na região. 0 nome da escola é uma homenagem aos doadores do terreno provenientes do Sul do Brasil, onde as Araucárias são abundantes. Na última década, com a chegada de novos grupos e famílias, o número de estudantes se ampliou, e, consequentemente, a diversidade dos pertencimentos e origens culturais presentes na escola se expandiu. Ou seja, também é recente a coexistência desses diversos grupos sociais e étnicos no contexto escolar.

0 Quadro 1 e o Gráfico 1, apresentados na seção anterior, oferecem uma imagem da diversidade cultural que compõe a Rota do Cavalo e de como essa diversidade, por grupo social e étnico, se expressa em percentuais de matrículas na Escola. A maioria das crianças matriculadas são provenientes de famílias ou comunidades dedicadas ao cultivo da terra, ao turismo, à criação, muitas das quais exibem identidades étnicas e campesinas históricas, como os acampados de movimentos sociais de luta por terra e moradia (MST, MATR, MLT, MTST, FNL), assentados da Reforma Agrária, Ciganos e pequenos agricultores.

Na convivência com as comunidades, identificando suas singularidades, gestos e falas, observamos que as crianças tanto mais afirmam suas identidades quanto mais a Escola oferece marcações positivas sobre suas origens culturais. lsso é particularmente perceptível entre as crianças ciganas da etnia Calon que frequentam a Escola. Esse reconhecimento afirmativo da própria identidade é acompanhado, contudo, de uma forte consciência, por parte das crianças, das dores e dos estigmas que seus pertencimentos identitários carregam.

Ao tratar da construção do conhecimento sobre si, Woodward (2009) sugere que a afirmação de nossas identidades particulares envolve pensamentos e sentimentos pessoais associados a um determinado contexto social. Ou seja, a cultura incide sobre a experiência que temos de nós mesmos, e é por meio dela que adotamos uma identidade cultural.

Perpétuo (2017), em pesquisa realizada na Rota do Cavalo e na Escola Classe Sítio das Araucárias, afirma que as crianças ciganas, ao falarem de si, se autonomeiam conforme seu espaço de vivência: "sou fulano cigano." Observamos que o mesmo ocorre com crianças 
não ciganas, que ao se apresentarem, afirmam: "sou beltrana do acampamento Margarida"; "sou fulana do condomínio Serra Verde"; "sou sem-terra, sou agricultor(a)."

Esse processo de identificação se dá ao longo da vida, pela tomada de consciência da própria diferença em contraste com o outro. Segundo Silva (2010), as identidades se tencionam, conflitam e disputam territórios, espaços e lugares, o que significa dizer que as diferenças são marcadas a partir de relações de poder. Ou seja, a afirmação das identidades envolve distinções entre o que fica dentro e o que fica fora da autoidentificação; entre o que somos e o que não somos. Dito de outro modo, afirmar a identidade implica demarcar fronteiras entre o "nós" e "eles" - o que é também uma forma de distinção e de classificação.

Essa ideia amplia nossa compreensão sobre a forma como as identidades das(os) estudantes são forjadas em seus cotidianos e territórios; e, em contraste, como podem ser negadas e/ou marcadas negativamente na dinâmica da Escola. Com efeito, se a construção da identidade e da diferença caminham juntas, isso demanda uma maior sensibilidade por parte das(os) educadoras(es) no sentido de oferecer condições para que as identidades sejam valorizadas e coibir processos de exclusão, discriminação e violências que podem decorrer da marcação negativa das diferenças.

Em seus territórios de vivência, as crianças também experimentam processos de afirmação, negação, marcação e comunhão de suas identidades, em razão da forma pela qual cada grupo assume suas identidades históricas e forja seus modos de vida, suas formas de interação com a terra e seus costumes. No sentido proposto por Hall (2009, p. 108), suas identidades são "[...] multiplamente construídas ao longo de discursos, práticas e posições que podem se cruzar ou ser antagônicas. Estão sujeitas a uma historização radical, constantemente em processo de mudança e transformação."

Os acampados e assentados, por exemplo, entendem que suas identidades são construídas, primeiramente, a partir da luta pela terra; e é por meio da luta que as condições necessárias à sobrevivência são produzidas. Diferentemente, as famílias agricultoras (pequenos proprietários) entendem que em primeiro lugar está a sobrevivência, que é garantida por meio do trabalho que possibilita comercializar os produtos da terra. Os Calon, por sua vez, na luta pela sobrevivência, abandonaram o nomadismo e assumiram uma condição de moradores fixos, alterando e ressignificando o comércio, a moradia, a religiosidade, o papel das mulheres e a escolarização de crianças e jovens do grupo.

Apesar de suas singularidades, para todos esses grupos a sobrevivência é, de algum modo, o motor cultural, o dispositivo que dispara processos em torno da manutenção e da modificação dos modos próprios de viver, da produção material da existência e, também, da produção e manifestação simbólica da vida: festejos, cantos, rezas, místicas. É novamente Hall (2009, p. 109, grifo nosso) quem lança luzes sobre essa questão: 
As identidades parecem invocar uma origem que residiria em um passado histórico com o qual elas continuariam a manter uma correspondência. Elas têm a ver com a questão da utilização dos recursos da história, da linguagem e da cultura para a produção não daquilo que somos, mas daquilo no qual nos tornamos. Têm a ver não tanto com as questões "quem somos" ou "de onde nós viemos", mas muito mais com as questões "quem nós podemos nos tornar", "como nós temos sido representados" e "como a representação afeta a forma como nós podemos representar a nós próprios. Elas têm tanto a ver com a invenção da tradição quanto a própria tradição [...]. Elas surgem com a narrativização do eu.

Foi isso que, em certo sentido, observamos entre os grupos sociais e étnicos com os quais interagimos na Rota do Cavalo. A identificação das crianças com seus grupos culturais se dá pela produção de um saber-fazer que define a trajetória de vida de seus integrantes e a principal atividade de trabalho desenvolvida por eles para a produção da existência. Ao se autonomearem pertencentes a um grupo, as crianças indicam a relação de seu grupo ou família com os saberes da principal atividade econômica que é repassada, pela experiência e oralidade, de geração em geração. Trata-se de uma autonomeação que define, ao mesmo tempo, sua identidade e sua ancestralidade.

Com efeito, quando a escola reproduz a marcação negativa das diferenças, não apenas menospreza esses saberes, mas também subalterniza os sujeitos que os produzem, as identidades que eles encarnam. Acentua, portanto, dores históricas provenientes da descriminação, o que concorre para fragilizar a identificação das crianças com seus territórios de vivência e com seus pertencimentos históricos e culturais.

Ademais, do que vimos por meio da interação com famílias e espaços comunitários de diferentes grupos sociais e étnicos, a presença dessas culturas na Rota do Cavalo e no cotidiano escolar também é atravessada pelos mesmos processos de racialização e subalternização presentes na constituição da sociedade brasileira (QUIJANO, 1992). Notese, por exemplo, que os preconceitos que marcam e estigmatizam, historicamente, famílias acampadas, assentadas e ciganas, são reproduzidos no espaço escolar, gerando conflitos, dificuldades de aprendizagem e evasão. Em razão disso, é importante reiterar a importância da valorização da diversidade cultural para promover o diálogo intercultural e um sentimento de comunhão em relação às identidades e culturas dos outros.

Percebe-se, de outra feita, que enquanto algumas crianças são educadas em seus territórios para sentirem orgulho e afirmarem suas identidades, como é caso dos assentados e acampados, outras experimentam processos de autonegação e desvalorização no próprio convívio comunitário. Quando a família e a escola falham no processo de afirmação e valorização das identidades, as crianças se tornam mais vulneráveis aos processos que 
as estigmatizam e marcam negativamente. Pérpetuo (2017) enfatiza que essa postura faz parte dos processos de negação aos quais as culturas subalternizadas foram submetidas, e que dessa situação nasce a instabilidade, a insegurança e a rejeição do grupo ao qual se pertence e da identidade que nele se compartilha.

No caso das crianças provenientes de espaços ligados a outras práticas de manejo da terra, como meeiros, criadores e famílias que trabalham com o turismo rural, observa-se que embora estas enfrentem também processos de marcação negativa de suas origens e pertencimentos, elas encontram na escola, por parte dos docentes, discursos de valorização e afirmação dos seus saberes. Aqui é flagrante uma postura mais afirmativa da escola, quando colocamos em paralelo a visão negativa e preconceituosa que identificamos em relação aos assentados e acampados.

A esse respeito, Hall (2009, p. 109) afirma que as identidades "[...] emergem no interior do jogo de modalidades específicas de poder e são, assim, mais o produto da marcação da diferença e da exclusão do que o signo de uma unidade idêntica, naturalmente constituída, de uma identidade' em seu significado tradicional." Compreende-se, portanto, que os processos de subalternização ou valorização construídos historicamente acerca de determinadas identidades e modos de vida também estão presentes na forma como a escola as olha, classifica e hierarquiza. Isso explica, por exemplo, a valorização das identidades, saberes e modos de vida ligados ao turismo e a dificuldade de se promover ações e projetos que comunguem e valorizem outras identidades e saberes (ciganas, acampadas, assentadas), que também compõem a diversidade cultual local.

É compreensivo, e até mesmo inevitável, que diferentes identidades culturais sejam tensionadas e friccionadas quando convergem para um mesmo tempo-espaço. Contudo, é responsabilidade ético-política da escola, enquanto território educativo e do encontro, promover o convívio e a valorização respeitosa das diferenças. Cabe à escola desenvolver competências dialógicas visando à comunhão entre diferentes identidades, saberes e modos de vida, como alternativa à perspectiva monocultural do conhecimento que:

Se manifesta pelo privilégio dos conhecimentos científicos e pelo preterimento
dos conhecimentos trazidos das experiências cotidianas, dos saberes
populares, das práticas da tradição. Os filhos das classes populares, não
raro, encontram nos espaços escolares a negação de suas origens, de
seus pertencimentos, de suas heranças étnicas e religiosas pela negação
de sua linguagem e de sua fala. Do mesmo modo, são simbolicamente
violentados por um discurso que privilegia os saberes e os padrões
ocidentais hegemônicos e relega ao esquecimento suas heranças que,
quando lembradas, são tratadas folcloricamente. (REIS DA SILVA, 2015, p. 476). 
Desse modo, sendo o encontro e a convivência entre as diferenças uma dimensão inerente ao espaço escolar, é imperativo que aqueles que são responsáveis pelas ações pedagógicas estabeleçam diálogos e construam estratégias com vistas à valorização das singularidades, promoção e o reconhecimento das alteridades, interação e comunhão da e na diferença. A convivência com outras culturas no processo de escolarização nos dá a oportunidade de desnaturalizar preconceitos contra certos grupos (sociais e étnicos), que, historicamente, foram não apenas identificados como "diferentes", mas classificados como inferiores em razão de suas diferenças. Essa classificação/hierarquização tem servido, como sabemos, para justificar toda sorte de discriminação e exclusão.

0 encontro, com efeito, comporta uma dimensão pedagógica estratégica para a desconstrução das visões estereotipadas acerca de povos cujas identidades, saberes e modos de vida, têm sido historicamente marcados pela racialização e desumanização. Afinal, quando nos abrimos à convivência com outros universos culturais, e com os sujeitos que os produzem, é que forjamos a experiência do encontro como lugar de formação e de transformação, tanto para quem convive com o novo quanto para quem vê sua cultura sendo reconhecida e experimentada por outros (HALL, 2009).

$\mathrm{Na}$ escola, essa postura deve partir das(os) docentes, isto é, daquelas(es) que planejam as ações e estratégias pedagógicas. Por isso, conhecer as identidades culturais que se expressam e atravessam a escola é fundamental. Se esse reconhecimento não for possível por meio da interação direta nos territórios de vivência dos estudantes, que seja através da formação docente e/ou de projetos escolares coletivos em que os próprios estudantes sejam protagonistas e possam compartilhar, em seus próprios termos, a percepção que têm sobre suas origens comunitárias, identidades, pertencimentos e modos de vida.

\section{A DIUERSIDADE CULTURAL NO CONTEXTO ESCOLAR}

Primeiramente, é preciso dizer que há uma preocupação genuína por parte da equipe docente da Escola Classe Sítio das Araucárias com vistas a implementação de estratégias voltadas ao acolhimento da diversidade cultural, conforme previsto na meta oito do Plano Distrital da Educação (PDE). A esse propósito se dedicam ações, como a construção do Inventário Social, Histórico, Cultural e Ambiental da Escola e a realização de atividades de integração entre os territórios de vivência e a comunidade escolar, favorecendo a presença e a participação de lideranças comunitárias. Foi o que constatamos em alguns relatos coletados 
durante as rodas de conversa, proferidos por educadores que ocupam diferentes funções no espaço escolar: 4

Na convivência dos anos fui conhecendo sobre eles. São muitos anos atuando aqui. Alguma coisa a gente planeja e pergunta sobre a vida deles, outras saem em conversas casuais. Fiquei sabendo que eles possuem uma organização dentro do acampamento, que cada familia tem dia para ficar na portaria para ajudar em algumas tarefas. Mas, conhecer e aprofundar aconteceu ultimamente, através do Inventário, roda de conversa e estudos, então, assim que aprendi mais sobre a Rota. (Professora 6).

Quando cheguei, vocês falavam desse Inventário, mas para mim era só uma sondagem. Daí conheci o Inventário que a escola já tinha feito nos anos anteriores, fui ver do que se tratava e o que fizeram. E quando fomos fazer outras atividades para complementar eu fui entendendo o lugar, as dificuldades. Vi o vídeo e fotos de vocês indo nas casas e então quando uma familia teve dificuldade eu me engajei em ajudar e conheci melhor a Margarida Alves e fui saber sobre o Abrigo. (Coordenadora 1).

Acho que essa educação aí voltada para a diversidade está caminhando. Cheguei tem pouco tempo, mas o que vejo é que a escola produziu bastante sobre as famílias das crianças daqui. Vi que $\circ$ grupo, antes mesmo de eu estar aqui, buscou conhecer o contexto, mas que mesmo assim, no ambiente da escola há muito o que ser feito sobre [...] diversidade, de falar das diferenças. Inclusive das nossas diferenças, dos nossos pontos de vista, do nosso modo de ser. A escola tem o Inventário do campo e acho que podemos agora analisar ainda mais 0 contexto e analisar qual a situação da escola que ele, o aluno, está inserido, a manifestação cultural que está naquela localidade tal e assim casar com um currículo que abranja mais a nossa realidade comunitária. Ver mais se estamos dentro da Lei, das diretrizes. Eu mesma não tinha noção de como era trabalhar com crianças de abrigo. Aqui está sendo um aprendizado. (Gestora substituta) (informações verbais).

Ao afirmarem conhecer as singularidades culturais das crianças, casualmente ou por meio de projetos, as docentes demonstram que a diversidade não passa desapercebida, e que há uma abertura ao acolhimento das diferenças na organização do trabalho pedagógico. Nos relatos, o que se observa é um interesse genuíno por esses mundos outros que as crianças comunicam a partir de seus pertencimentos, o que pode ser um indicador positivo de que a Escola se movimenta intencionalmente para valorizar a diversidade e ressignificar as práticas pedagógicas.

4 Visando preservar o anonimato das nossas interlocutoras, suas falas serão identificadas pelas funções que ocupam, seguido de número quando se tratarem de várias pessoas em uma mesma função. Cumpre informar, ainda, que todas as pessoas que participaram da pesquisa assinaram um termo de consentimento livre e esclarecido no qual autorizam a referência de suas falas em caráter de anonimato. 
Entendemos que essa postura já é uma importante inflexão, sobretudo quando se considera que o desconhecimento sobre a cultura do outro constitui uma barreira ao diálogo respeitoso entre os diferentes. Afinal, se a escola é um espaço onde as diferenças culturais coexistem inevitavelmente, os encontros também são, inescapavelmente, marcados por processos de negação, afirmação, marcação da tolerância e/ou comunhão da diferença. Podem, portanto, ser experimentados como estranheza, como barreira ao diálogo, mas também como oportunidades para a construção de práticas pedagógicas mais sensiveis que fomentem um processo de auto e hetero reconhecimento das diferenças e valorização entre elas.

Nas discussões desenvolvidas nas rodas de conversas, identificamos que múltiplos fatores interferem nas formas de acolhimento, interação e valorização das diversidades culturais. A rotatividade docente, por exemplo, interrompe o prosseguimento de ações voltadas a esse propósito, conforme é possível constatar nas falas das professoras:

[...] outra coisa que acontece muito na educação é a rotatividade, não só a de menino, mas a rotatividade de professor nas escolas que é muito desgastante [...]. De fato, desgasta tanto ○ trabalho pedagógico com $\circ$ administrativo. Barra as nossas ações. (Gestora em substituição).

Cheguei aqui em 2009 e desde sempre vejo essa rotatividade de professor atrapalhando mais que ajudando na execução dos projetos. Às vezes os colegas que chegam não entendem que as crianças daqui não são crianças da cidade, elas possuem outras vivências e por isso necessitam de um planejamento diferente. Mas aí parece que existe também um medo de admitir que precisa de ajuda. Também vejo que alguns educadores são inexperientes e não conseguem ressignificar as práticas e que outros talvez tenham dificuldade de fazer esse elo com um currículo aberto. (Professora 6) (informações verbais).

Não apenas nessas falas, mas em toda a equipe docente persiste esse sentimento de que a rotatividade é a principal causa do não envolvimento das(dos) professoras(es) com os projetos pedagógicos que visam construir uma integração entre os saberes escolares e os saberes que as(os) estudantes trazem de suas vivências comunitárias. Entendemos, com isso, que a equipe reconhece a potência educativa dos saberes que permeiam a diversidade cultural da Rota do Cavalo e estão dispostos a integrá-los nos processos formativos das(os) estudantes, mas ainda buscam formas de superar os obstáculos que limitam a realização plena desse propósito.

Os preconceitos e os estigmas sociais também são vistos pela equipe docente como uma barreira ao acolhimento da diversidade cultural. As três falas a seguir nos ajudam a entender, desde a perspectiva das professoras, o modo pelo qual o preconceito funciona 
como um mecanismo de marcação negativa das diferenças que suscita, por sua vez, um processo de auto e hetero negação das identidades:

\begin{abstract}
Eu vejo que os ciganos sofrem um pouco de preconceito, não pelas crianças, mas pelos pais das crianças de outros grupos, inclusive daqueles que também passam por situações de exclusão social como é o caso dos sem-terra. Na reunião bimestral teve uma mãe me pedindo para separar o filho deles dos alunos ciganos. Achei estranho, mas ainda não sabia nada da escola e depois fui me inteirar do assunto. (Professora 1).
\end{abstract}

Falam mal do povo sem nem ir ao lugar ou sem nunca conhecer. Quando criança sempre escutei falar mal dos ciganos. Quando minha familia soube que eu tinha alunos ciganos já falaram para eu ter cuidado. Aí fui dizer, "que isso, moçol" A gente até ficou receoso quando íamos trazer os lideres ciganos para debaterem na escola, porque tem muita gente preconceituosa que poderia entender errado. 0 preconceito já está na história. Outra coisa é quando a gente vai para um encontro de escolas, cursos. Têm colegas professores que acham que quem trabalha na escola do campo tem que se vestir deselegante, e que trabalhamos com o personagem Jeca Tatu, ou piolhentos, ou quando a gente fala que tem acampados e ou meninos de abrigo já vem com a história de que são mal-acostumados, que as crianças do abrigo têm Aids, usam droga e pode ser arriscado. É muita barbaridade que se escuta e que sai da boca das pessoas. Falta respeito e empatia até nos profissionais da educação. (Professora 3) linformações verbais).

Chama-nos a atenção a consciência aguda que as professoras demonstram ter acerca dos processos de marcação negativa das diferenças, assim como da naturalização das condutas que estigmatizam e propagam preconceitos contra grupos historicamente marcados. Trata-se de estereótipos que não apenas classificam, mas também geram processos de subalternização dos sujeitos, de suas identidades, de seus corpos, de suas elaborações culturais, saberes, memórias e tradições. Esse processo diz respeito às colonialidades do poder, do ser e do saber (QUIJANO, 1992) que atravessam a nossa experiência histórica moderno/colonial. Compreender criticamente como essas colonialidades operam na racialização das pessoas, dos mundos e saberes que elas comunicam, é imprescindível em qualquer projeto educativo que busca valorizar a diversidade e seu potencial pedagógico.

Nesse sentido, o relato da professora 1 é tanto uma denúncia da violência que envolve a inferiorização de determinada cultura quanto um lamento pela constatação de que mesmo aqueles que são marcados pelo preconceito também os reproduzem contra grupos que se encontram em posição similar de subalternidade. Isso demonstra que os processos de classificação, hierarquização e racialização engendrados pela colonialidades do poder, do ser e do saber operam também nos imaginários dos grupos subalternizados que reproduzem contra seus iguais as mesmas violências dos quais são vitimas. 
É importante notar que o preconceito nem sempre é expresso por meio de violência física, mas, sobretudo, por meio de posturas e discursos que vão naturalizando e propagando uma imagem negativa do outro. Assim, o preconceito assume a forma de tolerância em relação ao outro, de postura que evoca, ao fim e ao cabo, uma falsa aceitação das diferenças. Para Marques (2012), a tolerância é uma forma de não evidenciar a negação e, nesse sentido, é um preconceito ainda mais arrogante porque parece conferir a quem descrimina negativamente o poder de conceder ao diferente uma licença para existir.

A estigmatização é, segundo as professoras, uma das principais causas da negação e da marcação negativa dos pertencimentos culturais das crianças no processo de escolarização. Logo, implementar projetos de acolhimento da diversidade cultural é um caminho para o enfrentamento dessas violências, a fim de valorizar e dar visibilidade às singularidades que compõem a comunidade escolar; enfim, para combater a exclusão e a descriminação em razão das diferenças.

Por isso mesmo, o encontro intercultural, que é inescapável, deve ser potencializado para proporcionar o diálogo intercultural. Nos termos propostos por Walsh (2012), é preciso superar a perspectiva celebratória da "interculturalidade relacional", que ao tempo que constata a diversidade, oculta, minimiza e nega os conflitos aí subjacentes. Do mesmo modo, é preciso evitar as armadilhas de uma "interculturalidade funcional ao sistema" que propaga a tolerância como forma de apaziguar as tensões, evitando problematizar as relações de poder que classificam, hierarquizam e racializam pessoas em razão de suas diferenças. 0 que Walsh (2012) propõe é, em outra direção, uma "interculturalidade crítica" na qual a diversidade seja compreendida como construção social, problematizada enquanto mecanismo de discriminação e racialização e fortalecida como potência político-pedagógica.

A propósito da interculturalidade crítica, há um exemplo emblemático no contexto pesquisado. Enquanto em seus contextos familiares e comunitários as crianças participam ativamente das tarefas voltadas à produção da vida cotidiana, na escola aprendem que a participação das infâncias no trabalho familiar pode ser criminalizada como trabalho infantil, ou que a própria ação militante que marca a trajetória de seus grupos (como acampados e assentados) não é uma forma de aprendizado e conhecimento. Com efeito, como nos indica uma das coordenadoras da escola, a integração entre educação escolar e vivência e a inclusão dos saberes e das experiências dos estudantes nos processos pedagógicas não dependem apenas de se dominar os instrumentos didáticos:

Temos muitos alunos do movimento social, eles que nos provocam. Mesmo que não peçam pra falar sobre eles, eu como professora aprendi que é preciso falar sobre eles. É importante jogar o olhar para o nosso modo de trabalhar, porque a presença deles por si só, os corpos deles aqui na escola nos pedem uma postura diferente dessa forma eurocentrada de ver 
o mundo. Listar conteúdo, limitar que parte da história ou da matemática eu vou trabalhar em sala é ser injusto com os saberes que essas crianças já possuem. [...] Antes também concordava que era um absurdo menino faltar na aula para ir em ação na Esplanada, ou lá no acampamento. 0 curso sobre educação do campo do MEC me ajudou. Hoje, aprendi a mudar meu olhar, e sei que os movimentos sociais quando saem lá na Esplanada reivindicando as terras deles é uma forma de viver e de educar, e a criança sem-terrinha quando vem aqui pra escola vai colocar em prática essa forma de reinvindicação quando ela se sentir deslocada, tipo na hora de receber alguma premiação, ou quando ela se sentir injustiçada, ou tipo ela vai perguntar porque teve tratamento diferenciado pela professora ou direção ou cozinheira e ela vai me fazer pensar se esse tratamento é em função da identidade dela. (Coordenadora 2) (informação verbal).

0 relato acima é um excelente exemplo de reflexão crítica sobre a prática docente, e também de como a aprendizagem é um processo retroalimentado na relação, em que professoras(es) e estudantes aprendem uns com os outros. No caso da coordenadora, esse processo gera um conhecimento sobre si mesma, baseado não apenas na atuação profissional propriamente dita, mas que vem da convivência com o outro e que possibilita somar conhecimentos e ressignificar a prática docente. Experiências vistas por outros como barreiras, para esta coordenadora (que também já ocupou e ocupará a função docente), converteram-se em oportunidades de transformação pessoal e de afirmação positiva da diversidade cultural que os estudantes expressam.

Além disso, é importante notar a importância fulcral que a formação continuada desempenha como indutora de mudanças nas posturas das(os) professoras. Segundo o relato da coordenadora, foi justamente um processo formativo que the abriu caminhos para uma reflexão crítica e uma tomada de consciência sobre questões antes incompreendidas e vistas de forma preconceituosa, como, por exemplo, a educação que brota do próprio processo de luta pela terra e dos modos de vida dos acampados do MST.

Esse testemunho nos mostra como o encontro e o diálogo intercultural podem ser pedagogicamente potentes. São uma oportunidade para se romper com a visão hegemônica (colonial) que desqualifica os modos de vida dos povos campesinos, que classifica seus saberes próprios (não escolares) como "não saberes", que não reconhecem suas formas próprias de educar e de produzir sentidos. São, ademais, uma oportunidade para se assumir uma postura crítica e propositiva acerca da visão cientificista dos conhecimentos, ainda predominante nos currículos escolares. Inclusive porque, em um currículo

[...] baseado no privilégio da narrativa cientificista e em relações assimétricas de poder, a diferença adquire o caráter de estigma de modo que "um dos termos da diferença é avaliado positivamente (o 'não diferente') e o outro, negativamente (o 'diferente')". [...] Assim, o discurso da tolerância 
frequentemente encontrado nas próticas escolares, apesar de sua aparente generosidade, aporta certa superioridade por parte daquele que tolera. (REIS DA SILVA, 2015, p. 465).

Marques (2012) afirma que a consciência que o docente tem sobre a diversidade que permeia o contexto escolar resulta da compreensão de que os saberes podem se comungar sem se anular ou hierarquizar um ao outro, e que desta comunhão surge o acolhimento e a visibilidade das identidades historicamente silenciadas. Com efeito, formações e capacitações docentes sobre a temática da diversidade cultural, oferecidos pela própria escola, ou projetos voltados para a inclusão dessa temática na prática docente e nos currículos, são caminhos imprescindíveis para ressignificar velhas posturas. Ou seja, um giro transformacional da realidade demanda uma formação docente mais consistente que fomente uma compreensão crítica da educação voltada à população do campo, suas especificidades, demandas e formas próprias de viver.

Lacunas formativas obstaculizam uma visão ampla e crítica acerca da escola enquanto comunidade de aprendizagem que é constituída e atravessada pela diversidade cultural na qual está inserida. Do mesmo modo, criam entreves para o protagonismo docente na construção de práticas pedagógicas que valorizem as origens, os saberes e os pertencimentos identitários das(os) estudantes.

Durante as rodas de conversa, as professoras indicaram outros pontos que, segunda elas, fragilizam uma atuação pedagógica mais sensivel ao contexto, com respeito e consideração à diversidade cultural das(dos) estudantes: a hierarquização das funções; a carência de apoio pedagógico para apoiar a construção de novas estratégias curriculares; a resistência às mudanças; dificuldades para fomentar processos coletivos de troca de experiências sobre novas metodologias e inovações pedagógicas. É o que nos indicam os seguintes relatos:

Lembro de que fazer o Inventário é às vezes uma luta. A Secretaria já disse que temos que estudar as Diretrizes do campo, fazer o Inventário, que a educação do campo tem que acontecer, mas a gente esbarra com professores que se negam a mudar a forma de trabalhar. Querem livro, caderno e cópias. Mudar a cabeça do outro não é fácil. (Coordenadora 2).

0 que vejo é: se estamos numa escola que é do campo, tem que participar de formações do campo, estudar o que diz as diretrizes e o currículo do campo. Eu quando fui coordenadora meio que cansei de ter que explicar que o Inventário faz parte da nossa rotina, não é um outro projeto. (Professora 3) (informações verbais). 
Essas falas informam que apesar de a escola ter avançado na construção de documentos que embasam o acolhimento da diversidade cultural, ainda há muita resistência para converter essas mudanças em práticas pedagógicas pertinentes - algo que se observa no forte apego aos modelos convencionais. As atividades que exigem a colaboração de todos não são suficientes para motivar e mobilizar a equipe docente na construção de ações que valorizem os saberes e as formas de produção de sentidos dos grupos étnicos e sociais que compõem a diversidade da Rota do Cavalo. Ainda é um desafio fomentar uma consciência, uma sensibilidade e uma ação coletivas para aproveitar a potência pedagógica e epistêmica desses outros mundos, saberes e identidades, que, inevitavelmente, chegam, atravessam e constituem a escola.

Ademais, as professoras advertem que o desconhecimento das Diretrizes da Educação do Campo e dos instrumentos que regem o trabalho administrativo e pedagógico voltados para escolas rurais são obstáculos à promoção de estratégias pedagógicas que valorizem os saberes, as identidades e as culturas de povos subalternizados. Esse desconhecimento parece estar diretamente ligado também ao constante remanejamento docente e à presença de professoras(es) com pouca experiência em escolas rurais.

Esta, assim como outras fragilidades apontadas neste estudo, são entraves ao acolhimento da diversidade cultural visando a valorização e a comunhão das diferenças. A propósito disso, cumpre destacar como a noção de "tolerância" comporta uma falsa e perigosa ideia de respeito e valorização da diversidade. Skliar (2005) denuncia que muitas vezes a escola, ao tentar problematizar a temática da diversidade, acaba se atendo aos diferentes, e não às diferenças, e, assim, acaba aderindo ao discurso da tolerância, sobretudo em relação àqueles que são estigmatizadas por serem supostamente "menos normais".

Nos termos de Marques (2012, p. 106), ao "I...] pensarmos nos diferentes, nos estranhos, nos outros, a escola acaba por propiciar o processo de normalização de seus alunos e de suas alunas." Em síntese, esta pesquisa evidenciou que a Escola ainda opera no marco da tolerância, tendo avançando pouco na problematização dos conflitos e fricções que surgem do encontro das diferenças e no como agir, para, em outra direção, fortalecer a diversidade cultural como potência pedagógica e epistêmica.

\section{O ENCONTRO COMO POTÊNCIA PARA O DIÁLOGO E A EDUCAÇÃO INTERCULTURAL}

Do que se viu até aqui, ao tempo que a escolha busca acolher e visibilizar a diversidade cultural, também reproduz processos de marcação negativa das diferenças, o que tem se mostrado como um obstáculo à construção de práticas pedagógicas que visem 
uma integração entre os conhecimentos escolares e os saberes que os estudantes trazem de suas experiências. Contudo, não seria correto afirmar que essa dificuldade de valorizar e integrar a diferença se dá de forma consciente e deliberada. 0 cotidiano dinâmico da escola, quase sempre voltado para o cumprimento das tarefas didáticas e administrativas, muitas vezes se torna uma barreira para a promoção de diálogos mais amplos e sensíveis ao acolhimento da diversidade cultural.

Muitos dos relatos das(os) professoras(es) sugerem que, embora tentem, nem sempre é possível comungar os conhecimentos escolares com os saberes próprios das(dos) estudantes. Isso pode expressar tanto uma dificuldade (ou indisposição) para compreender a potência pedagógica da diversidade cultural quanto os limites da formação e a rotina exigente do cotidiano escolar. 0 testemunho de uma professora demonstra que forjar uma consciência aguda e mais sensível sobre a realidade onde se atua leva tempo e demanda engajamento:

\footnotetext{
Uma coisa que compreendi nesses 11 anos é que não basta você atuar na escola do campo, é preciso também buscar entender sobre a vida deles que moram e vivem dessa cultura do campo. Visitar a casa, as festas, ir nos lugares que eles também frequentam igual a gente foi em passeio no Flor do Cerrado, lá no Jorge, igual a gente foi lá nos ciganos, no MST, na lavoura da aluna, na Feira da Lua. Saber do que gostam, entender por que nos acampamentos tem portaria, por que no abrigo tem que agendar para entrar, e assim vai. (Professora 6) (informação verbal).
}

Também constatamos que as ações da Escola em prol do mapeamento e da valorização dos saberes que constituem a região Rota do Cavalo são, quase sempre, meramente descritivas, inclusive aquelas encontradas na Proposta Pedagógica de Trabalho e Inventário Patrimonial. Isso reforça a necessidade da construção de caminhos que fomentem a valorização dos saberes, identidades e vivências das(os) estudantes para além da mera interculturalidade relacional e/ou da simples inclusão formal e funcional da diversidade no espaço escolar. Isto é, no sentido de uma interculturalidade crítica, é preciso avançar para uma compreensão das desigualdades que são produzidas em razão das diferenças e, ao mesmo, para a valorização da potência pedagógica e epistêmica da diversidade.

Segundo Walsh (2012), é preciso entender que o encontro é inevitável, mas é preciso agir intencionalmente para que ele proporcione um diálogo intercultural e, consequentemente, converta-se em oportunidade para a educação intercultural criticamente orientanda. Dito de outro modo, promover a interculturalidade não é simplesmente questionar a lógica hegemônica; é preciso identificar e enfrentar as relações de poder, isto é, as colonialidades (do poder, do ser e do saber) que radicalizam e subalternizam os povos tradicionais e seus modos de ser/ estar e sentipensar no mundo. 
Basei e Leães Filho (2008), em pesquisa sobre a interculturalidade na formação de professoras(es), alertam para a reprodução de práticas pedagógicas fundamentadas em ações homogeneizadoras em torno de um currículo monocultural que ignora e silencia a diversidade comunitária, supervalorizando o conhecimento científico e subalternizando outros sistemas de conhecimentos (saberes populares, de povos e comunidades tradicionais, etc.).

Autores vinculados ao pensamento decolonial (CASTRO-GÓMEZ; GROSFOGUEL, 2007; MIGNOL0, 2008) tem buscado pensar esses processos como racismo epistêmico e epistemicídio - enquanto subproduto do racismo de cor - justamente por produzirem invisibilidade e pagamento de todo tipo de conhecimento não produzido e legitimado sob a égide da ciência moderna. Essa violência epistêmica tem efeitos nefastos para crianças em processo de escolarização, cujas referências culturais são desvalorizadas e apontadas como inferiores em relação ao conhecimento escolar cientificamente informado.

Santos e Almeida Filho (2008) entendem a injustiça cognitiva como uma postura arrogante do conhecimento científico em relação aos saberes dos povos e comunidades tradicionais (indígenas, quilombolas, camponesas) que operam com outros sistemas de conhecimento, com repertórios e protocolos baseados na oralidade. Os autores lembram que, se o mundo é plural - e de fato é -, os saberes são inter-relacionais, interdependentes e complementares. Nesse sentido, como alternativa à perspectiva monocultura do conhecimento que ainda predomina nos currículos escolares, propõem a pluralidade epistêmica e o diálogo de saberes visando promover a colaboração entre distintos sistemas de conhecimentos (científicos, tradicionais, populares).

Para Santos (2006), com efeito, a promoção da justiça cognitiva demanda a denúncia e o enfrentamento das relações de poder/saber no processo de produção e legitimação do conhecimento, o que envolve compreender a lógica sob a qual o privilégio de um conhecimento opera sobre o outro, subalternizando-o. No caso da ciência moderna, o conhecimento parece ser produzido em um lugar protegido do mundo, onde o próprio mundo com suas diversidades e singularidades fica "do outro lado da porta". Ou seja, "o privilégio epistemológico que a ciência moderna se arroga pressupõe que a ciência é feita no mundo, mas não é feita de mundo." (SANTOS, 2006, p. 138).

Em uma perspectiva epistêmica plural, promover justiça cognitiva implica o convívio e o diálogo simétrico entre distintos sistemas de conhecimento. Implica valorizar e reconhecer a validade e a legitimidade de outros saberes e seus enunciadores, reconhecendo que eles informam outros modos de sentipensar e outros sentidos de mundo. Portanto, a justiça cognitiva é uma forma de se relacionar, uma tradução e um diálogo intercultural que gera um tensionamento respeitoso entre saberes oriundos de contextos diversos; é também uma forma de enfrentamento aos privilégios, hierarquias e desigualdades geradas em razão do locus de enunciação a partir dos quais as pessoas se situam no mundo. 
0 diálogo intercultural é tão mais favorecido diante de experiências desafiadoras, pois elas exigem soltar as amarras que marcam negativamente as diferenças para favorecer a colaboração entre os saberes locais e os conhecimentos escolares. $0 \mathrm{u}$, como sugere Fonseca (1995), é preciso ir da marcação negativa das diferenças para o reconhecimento e o respeito às diferenças. A marcação das diferenças opera a partir de dicotomias do tipo normal versus anormal, superior versus inferior, capaz versus incapaz, e assim por diante, mantendo e reproduzindo as colonialidades de poder, ser e saber (MIGNOLO, 2008).

A valorização da diversidade cultural em seu sentido radical, enquanto dimensão inerente e constitutiva do encontro, é um caminho para a promoção de aprendizagens significativas baseadas na própria comunhão das diferenças. Segundo Marques (2012, p. 108), “[...] a comunhão com as diferenças é mais do que um simples ato de tolerância, é a afirmação de que a vida se amplia e se enriquece na multiplicidade. Ser diferente não significa mais ser o oposto do normal, mas apenas ser diferente."

Esse "sentido de comunhão" não encontra lugar em contextos escolares que hierarquizam os pertencimentos, as identidades, os modos de vida e os saberes que atravessam as experiências e trajetórias dos estudantes. Ocorre que, se comunhão exige reconhecimento e valorização da diversidade cultural, o diálogo e a colaboração entre

distintos sistemas de conhecimento e seus produtores é o único caminho plausível. É por essa via que a escola se fortalece como lugar do encontro, do diálogo e como espaço de educação intercultural crítica, que, por sua vez, retroalimenta, expande e qualifica o encontro intercultural enquanto processo pedagógico. Assim, e por meio desse reforço mútuo entre encontro, diálogo e educação intercultural, a escola pode também fomentar e fortalecer os laços de fraternidade e solidariedade entre os grupos subalternizados.

\section{CONSIDERAÇÕES FINAIS}

Neste artigo, argumentamos que é possivel e necessário valorizar a diversidade cultural e promover a integração e o diálogo colaborativo entre os conhecimentos escolares e os saberes que as(os) estudantes aportam de suas trajetórias históricas e experiências comunitárias. Essa tarefa exige, contudo, engajamento e capacitação da equipe docente, de modo que o encontro (inescapável) entre os diferentes se converta na valorização de saberes outros e na promoção do diálogo e de uma educação intercultural crítica.

Observamos, ao longo da pesquisa, que no processo de integração e convivência da diversidade produzem-se estranhamentos que notadamente se traduzem em formas de subalternização e racialização de determinados grupos sociais e étnicos. Algo que decorre, em 
larga medida, dos imaginários racistas que marcam a nossa experiência moderno/colonial. Com efeito, o encontro e o diálogo intercultural parece sempre permeado por contradições, pois envolve, ao mesmo tempo, processos de negação, afirmação, marcação e comunhão das diferenças.

Ao se abrir para o diálogo com a diversidade cultural que a envolve e a atravessa, a escola amplia sua função social de garantir uma aprendizagem significativa, visto que inclui aí a possibilidade de promover justiça cognitiva e epistêmica. Ou seja, ao se constituir como um espaço de acolhimento e valorização das identidades, saberes e modos próprios de viver e produzir a existência dos povos historicamente subalternizados, a escola alia a garantia do direito a uma educação diferenciada a um processo de reparação dos racismos e epistemicídios historicamente reproduzidos dentro e fora do espaço escolar.

Por fim, é preciso dizer que o diálogo entre os conhecimentos escolares cientificamente orientados e os saberes que emergem da experiência, da vida em comunidade, da luta por direitos, não apenas promove justiça epistêmica e cognitiva, mas também, e consequentemente, garante uma aprendizagem significativa para estudantes historicamente racializados e estigmatizados.

No contexto da pesquisa em questão, o encontro e o diálogo entre as diversidades culturais que chegam e atravessam a Escola apontam para a oportunidade de uma educação intercultural e significativa. Algo que se mostra mais como potencialidade do que como realidade, e que, portanto, ainda precisa ser adequadamente compreendida pela comunidade escolar para se converter, de fato, em um caminho pedagógico alternativo.

\section{REFERÊNCIAS}

BASEl, A. P.; LEÃES FLLHO, W. A interculturalidade na formação de professores: possibilidades de (re) significar as práticas da Educação Física escolar. Revista Digital, ano 12, n. 117, fev. 2008. Disponível em: https://www.efdeportes.com/efd117/a-interculturalidade-na-formacao-de-professores-da-educacao-fisica.htm. Acesso em: 7 jun. 2019.

CASTRO-GÓMEZ, S.; GROSFOGUEL, R. (ed.). El giro decolonial: reflexiones para una diversidad epistémica más allá del capitalismo global. Bogotá: Siglo del Hombre Editores; Universidad Central, Instituto de Estudios Sociales Contemporáneos y Pontificia Universidad Javeriana, Instituto Pensar, 2007. Disponivel em: http:// www.unsa.edu.ar/histocat/hamoderna/grosfoguelcastrogomez.pdf. Acesso em: 14 jul. 2020.

FONSECA, V. da. Educação especial. 2. ed. Porto Alegre: Artes Médicas, 1995.

GOVERNO DO DISTRITO FEDERAL. Diretrizes Pedagógicas da Educação Básica do Campo: para a rede Pública do Distrito Federal. Brasilia, DF: Secretaria Distrital de Educação, 2018. Disponível em: http:// www.educacao.df.gov.br/wp-conteudo/uploads/2018/01/Diretrizes-Ed-do-Campo-SEEDF.pdf. Acesso em: 14 jul. 2020. 
HALL, S. Quem precisa da identidade? In: SILVA, T. T. (org. e trad.). Identidade e diferença: a perspectiva dos estudos culturais. Petrópolis, RJ: Vozes, 2009. p. 103-133.

MARQUES, L. P. Cotidiano escolar e as diferenças. Educação em Foco, v. 17, n. 11, p. 101-117, mar./jun. 2012. Disponivel em: https://www.uff.br/revistaedufoco/files/2012/10/Cotidiano-escolar-e-diferenças. pdf. Acesso em: 14 jul. 2020.

MIGNOLO, W. D. El pensamiento decolonial: desprendimiento y apertura. Un manifiesto. In: CASTRO-GÓMEZ, S.; GROSFOGUEL, R. (org.). El giro decolonial: reflexiones para una diversidad epistémica más allá del capitalismo global. Bogotá: Siglo del Hombre Editores, 2008. p. 25-46.

PERPÉTUO, L. D. Comunidade cigana Calon em processo de escolarização: conflitos étnicos e saberes pluriculturais. 2017. 153 f. Dissertação (Mestrado em Educação) - Universidade de Brasília, Brasília, DF, 2017. Disponivel em: https://repositorio.unb.br/handle/10482/31549. Acesso em: 14 jul. 2020.

QUIJANO, A. Colonialidad y modernidad-racionalidad. Peru Indigna, v. 13, n. 29, p. 11-20, 1992. Disponível em: https://www.lavaca.org/wp-content/uploads/2016/04/quijano.pdf. Acesso em: 14 jul. 2020.

REIS DA SILVA, A. T. Educação em direitos humanos: o currículo entre o relativismo e o universalismo. Educação e Sociedade, v. 36, n. 131, abr./jun. 2015. Disponivel em https://www.scielo.br/scielo. php?pid=S0101-73302015000200461\&script=sci_arttext\&tlng=pt. Acesso em: 26 fev. 2021.

SANTOS, B. de S. A gramática do tempo: para uma nova cultura. São Paulo: Cortez, 2006.

SANTOS, B. de S.; ALMEIDA FLLHO, N. de. A universidade do século XXI: para uma universidade nova. Coimbra: Almedina, 2008.

SILVA, T. T. da. Documento de identidade: uma introdução às teorias do currículo. 3. ed. Belo Horizonte: Autêntica, 2010.

SKLIAR, C. A questão e a obsessão pelo outro em educação. In: GARCIA, R. L.; ZACCUR, E;; GIAMBIAGI, I. (org.). Cotidiano: diálogos sobre diálogos. Rio de Janeiro: DP\&A, 2005. p. 49-62.

WALSH, C. Interculturalida y (de)colonialidad: perspectivas críticas y políticas. Visão Global, v. 15, n. 1-2, p. 61-74, jan./dez. 2012. Disponível em: https://portalperiodicos.unoesc.edu.br/visaoglobal/article/ view/3412. Acesso em: 14 jul. 2020.

WOODWARD, K. Identidade e diferença: uma introdução teórica e conceitual. In: SILVA, T. T. (org. e trad.). Identidade e diferença: a perspectiva dos estudos culturais. Petrópolis, RJ: Vozes, 2009. p. 7-72.

Endereço para correspondência: Asa Norte, 70910-900, Brasília, Distrito Federal, Brasil; anaterezareis@ unb.br 
